\title{
SOCIAL IMPACT OF GLOBALIZATION PROCESS IN THE CONTEXT OF A RURAL VILLAGE IN SRI LANKA \\ Upali Pannilage $^{1}$
}

\section{Abstract}

While globalization has been credited with expansion of world economies, improved communication among peoples of the world with a promise of a better future with greater access to new technologies and services; globalization has also been referred to negatively for the growing inequalities both within and between countries and has been viewed by some as the pursuit of material interests by dominant states and multinational companies. The present research was conducted to examine the research problem of ways and means of globalization process has influenced rural society in Sri Lanka and the factors that have contribute to this process and in which manner the rural communities respond to this process?. The study has followed mixed research methodology which uses both qualitative and quantitative data. Primary data were collected from a sample of villagers in Kudagama village in Rathnapura district of Sri Lanka using both qualitative and quantitative data collection methods. The theories, concepts and recent studies that are relevant to the research problem were reviewed to place the study in a broader theoretical framework. The study found that the globalization process has made considerable impact on the society especially socially, politically and culturally. The study concluded with that the traditional rural Sri Lankan society has been considerably influenced by the globalization process.

Keywords: Globalisation, Impact, Society, Village
${ }^{1}$ Department of Sociology, University of Ruhuna

pannila@hotmail.com

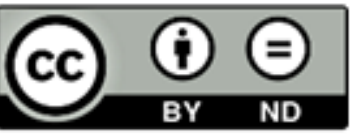

This article is published under the Creative Commons CC-BY-ND License (https://creativecommons.org/licenses/by -nd $/ 4.0 /$ ). This license permits use, distribution and reproduction, commercial and non-commercia, provided that the original work is properly cited and is not change anyway. 


\section{INTRODUCTION}

The rural society in Sri Lanka predominantly based on subsistence agriculture. Not only the economy but the social system too built on the agricultural process. Agricultural productions of the people were oriented towards their consumption and really on the exchange, but they were not oriented towards the market. While the rural economy is based on the agricultural production, the social system of the rural villages too was constructed to support the agriculture economy. There, the social structure was based on the self-governing systems, local leadership, and division of labour which largely based on the caste hierarchy, local beliefs and traditions.

The social, economic, political and cultural lives of rural Sri Lankan society were initially broken down with European encounters since 16th century. Since then, there are number of changes in the Sri Lankan society which contributed to reshape the rural society towards western style institutions, beliefs and practices e.g. modern bureaucracy and market economy. Introduction of various development interventions in line with international development practices further aggravated the situation in the country from its independence in 1948. Although this process of changes were not called as globalization those days, it is worth to study and find out those changes that have been taken place in the rural society in Sri Lanka in line with the globalization discourse. Therefore, the present study was conducted to examine ways that globalization process has influenced rural society in Sri Lanka? What factors have contributed to this process and in which manner the rural communities respond to this process?

This paper has organized under six sub sections. After the introduction, the objectives of the study have been clarified. Then, a brief introduction to the globalization has been provided in order to place the study in a theoretical framework The methodology section include the type and nature of methodology, study location, sample, methods of data collection and analysis. The latter part of the paper has been allocated for study findings, results and discussion and finally to draw conclusions.

\section{OBJECTIVES OF THE RESEARCH}

The broad objective of this research was to study social impacts of globalization process in the rural Sri Lankan society with a view of understanding and analyzing critical factors and making conclusions on the possible implications and corrective measures. In order the achieve this broader objective, a specific objective was formulated as to examine the ways and means that rural Sri Lankan society has globalized. Under this specific objective, the study was expected to find out critical factors that have contributed to the globalization process of rural society in Sri Lanka. It also looked in to the matters of comprehensive understanding of ways and means of globalization from the socioeconomic and political aspects.

\section{AN INTRODUCTION TO THE GLOBALISATION}

The term globalization has many specific uses in the academic discourse. It is frequently used as an economic term to denote the acceleration of the 
interconnections in the global economy. Khor, (2002:1) mentioned that economic globalization is not a new process, for over the past five centuries firms in the economically advanced countries have increasingly extended their outreach through trade and production activities (intensified in the colonial period) to territories all over the world. Youngs (2007:4) argued that the notions of an indirect persistence of United Nations of America's (USA) hegemony are most closely linked to the development of globalization perspectives. As per the views of Antonio (2004:176) the political economy of the USA has a profound financial, social, cultural and political influence on the process of globalization throughout the world. Much of earlier research in this field addressed the impact of trade liberalisation on aggregate welfare in developing nations or the relationship between trade liberalisation and poverty (McCorriston et al., 2013). Rosenau (2003) defined globalisation as the tensions between opposites that presently underline the course of events and the development or decline of institutions. Turner (2011) argued that as a consequence of globalization, modern societies are predominantly multi- cultural and consequently they are also multi-faith societies. Giddens (2009) defined globalisation as the intensification of worldwide social relations which link distant localities in such a way that local happenings are shaped by events occurring many miles away and vice versa.

These definitions highlight the close association of the term globalisation with the academic disciplines of economics, international relations, geography and sociology. More specifically the globalization means to the large-scale changes in the social economic and political life. Hence, it can be defined that globalization is a process of changes in various aspects of the society.

\section{METHODOLOGY FOLLOWED}

This study is based on mixed method research which both qualitative and quantitative data has been used concurrently. In the contemporary society, many social researchers preferred to employ combine methodologies to obtain counter balancing strengths of both qualitative and quantitative aspects. Since sociologist tends to study the social phenomenon of the society, they cannot limit to either quantitative or qualitative. As Olsen (2004) has explained, in social science triangulation is defined as the mixing of data or methods so that diverse viewpoints or standpoints cast light upon a topic. The mixing of data type is known as data triangulation'. The triangulation process can be used to change the qualitative/quantitative divide of the research and that is useful to identify different dimensions of the same phenomenon (Bryman, 2012).

The primary data for this study was collected from a rural village named Kudagama in Kalawana Divisional Secretariat Division (DSD) in Rathnapura district of the South Western Province (Sabaragamuwa) of Sri Lanka. This village comprises with four hamlets namely Kudagama, Pethiyakanda, Pitakele and Buthkande. The total land area of the area is 2472 acres. As results of wet climate, the area is full of vegetation from various kinds of large trees. Apart of this, the village is boundary to the world famous Sinharaja forest which is the largest forest in Sri Lanka and as well as one of the largest in the world. 
The total population of the area was 828 residing in 243 families. Out of the total population, $799(96.5 \%)$ are Sinhala Buddhist. The remaining 29 (3.5\%) of the population is belongs to the Sri Lankan Tamils and they are Hindus in religion wise. When considering sexual distribution of the population 421 of them were males and balance 407 were females. The economy of the Kudagama village was largely depends on the subsistence agriculture until recently. After the 1970s with the introduction of open and free market policies in to the country, the villagers in this village commenced tea cultivation and there by transformed to a cash crop economy.

The sampling of the study were done using both the random and nonrandom methods as the respondents to the qualitative data collection was selected through nonrandom methods of purposive and snowballing while respondents to the quantitative method (survey) was selected through simple random sampling method. A total of 142 persons of the village were included in the study sample.

Collection of primary data was done using various methods and tools. Observation method was used as the main methods of primary data collection. There both direct and indirect observations were conducted and participant observation also adjusted as appropriately and used to study the villagers' life in the study location. The community level qualitative information was collected through Focus Group Discussions (FGDs) while individual qualitative data were collected thought Key Informant Interviews (KIIS). Quantitative data was collected though a questionnaire which included both structured and non-structured questions.

Both the primary and secondary data were analysed largely through qualitative methods while using quantitative methods as appropriately. Primarily, two interrelated methods were used for qualitative data analysis namely the Thematic Analysis Method (TAM) and the method of Critical Discourse Analysis (CDA). The validations of data in the process of analysing were done through the triangulation. Prominent sociological theories of structural functionalist, symbolic interactionalist and conflict theory were used where appropriate to analyse the data.

\section{FINDINGS, RESULTS AND DISCUSSION}

There were number of western types of development interventions that have been introduced to the Kudagama village during the recent past. Those interventions include introduction and promotion of tourism, development of transport, road, electricity and other communication infrastructure and introduction of cash crops cultivation. Meantime, the time period of late 1970s can be considered as millstone that many interventions have been taken placed in this village. The local culture which is associated with the living patterns of the people in the village, and that has practiced by the villagers in the Kudagama village has considerably influenced by key interventions that has taken place as results of introduction of capitalist development process to the village. These development interventions that have been introduced to the Kudagama village can be categorized in to three main interrelated areas as follows. 
1. Infrastructures of transportation and communication

2. Interventions towards global governing mechanisms

3. Global trading and marketing systems

The study revealed that above mentioned three areas of interventions in the Kudagama village have interrelated changes and as well as individual impacts on the lives of people in the village. Since, Kudagama is one of the semi isolated habitant in the present globalised society, external interventions to the village under the name of development need to be understood in a broader sense. Therefore, the social impact of globalization process in the Kudagama village was discussed under these three broader areas.

\section{IMPACT OF INFRASTRUCTURES OF TRANSPORTATION COMMUNICATION

The analysis under this sub theme was based on two indicators namely, changes in family and marriages and also in social relationships. The study found that there was variety of impacts in the village as results of outside inputs of infrastructure in transportation and communication which has brought as results of globalization process. It was revealed that the traditional family and marriage system which are basic social institutions with direct links to the cultural practices of a village are slowly modernized due to the change process brought to the village by the globalization.

The primary data collected in the village on the family system has revealed that the traditional family system in the village is gradually changed due to various reasons which most of them seems outside to the village. The cases of divorces and separations are still not common in the village. But, few cases are now emerging which challenge the basic social unit of the society. The traditional extended family system which contributed considerably for the functions of the family is still remaining in the village, but to some lesser degrees. The extended family which also helped to the socialization process from generation to the generation is slowly changing and its place is taking over by the nuclear families. The autonomy that was existed in the family as the basic social institution in the society, to decide about the marriages and formation of family to continue the generation, has been challenged as the new system of formation of families through marriages are now taken over by the marriage couple themselves without considering their parents or grandparents. The motivation and influence from outside forces for these changes were evidenced from the primary data analysis.

Marriages are traditionally arranged by the families of the couple. "Love marriages" initiated by the couples themselves are, however, increasingly common. In the past, regardless of who initiates the marriage, the bride and groom are expected to be of the same socio-economic status, ethnicity, and, caste wise. Kinship was the main base for proposing a marriage. The caste system was considered as an essential factor for marriages. However, this system has changed considerably and there are many cases that some youngest has married from outside the village which their background of even the caste is not known to the others. In the past, there were many customs, values and norms connected with the marriage in the study location. The all customs occurred 
according to the auspicious time, matching the horoscopes etc. Wedding ceremonies were not common in Kudagama in the past, but there were simple gatherings of neighbors and relatives on the wedding day. Some of elders have not even registered their marriages initially, but have registered later on due to the motivation from the government to get married those who were not registered their marriages. And also those who were not officially married have motivated from their children to register their marriage. In the past, majority of marriages were taken place within the village, neighbors and same caste. However, there are considerable changes in the marriage and wedding ceremonies at present. Although, marriages are still taking place among the neighbors, relatives and caste groups, there are some cases that girls and boys get married without considering those aspects. Meantime, wedding ceremonies in hotels in the town has also getting popular in the village. Such changes contribute to the transformation of village autonomy from their own village to the outside individuals or groups in the market.

When consider about the social relations, the nature and type of social relationships represents cultural practices of the communities in the society. Pro-globalist arguments (eg Held, 1999) in this line of thinking are that globalisation contributes significantly to develop relationships worldwide due to the increased technologies and as well as opened up avenues for people to interact. Although, social relationships cannot be measured quantitatively, the study made an attempt to understand the nature and level of social relationships in the study location though the questionnaire survey. The study questionnaire included a question for respondents to priorities their relationships with neighbors, relatives who are living very close proximity to them, relatives living in distance and relationships with other organisations.

Accordingly, it was revealed that social relationships of communities in Kudagama are high with their neighbors as $64.4 \%$ of the respondents to the sample survey had mentioned that they have regular relationships with their neighbors. Meantime, none of the respondents have mentioned that they don't have relationships with their neighbors. The second highest number of relationships was observed with the religious organization (The Buddhist Temple) of the village where $53.4 \%$ and $28.8 \%$ had mentioned that they have regular or sometimes relationships with the religion institution respectively. Although, technically the distance is no matter for relationships in the era of globalization due to improved information communication technologies and increased access to those technologies by communities, the social relationships with distant relations were not satisfactory in the case of study location. Only $5.5 \%$ of respondents to the sample survey had mentioned that they have regular relationships with distant relatives while $12.1 \%$ respondents had mentioned that they don't maintain relationships with distant relatives at all.

Emile Durkheim (1858-1957) explained that there are two types of social solidary in the society namely the mechanical solidary and organic solidarity. The relationships that have been practiced in Kudagama village in the past, more or less similar to the mechanical solidarity as they had been built on social cohesion in the village. Meantime, moving away from such relationships indicates that people are no more maintain common social values and beliefs as they 
are moving towards independent nature where varying values and beliefs are being practices. This new social relationships can be understand as similar to the organic solidarity that described by Durkheim.

\section{IMPACTS OF GLOBAL GOVERNING SYSTEMS}

The study focused to understand social relationships of global governing system under two main thematic areas of formal and professional leadership and alienation in laws and systems which were identified as key outcomes of the interventions towards global governing mechanisms that are promoted by the globalization process. The analysis revealed that there were considerable interrelated changes that have been taken place in Kudagama village as results of implementation of global governing mechanism in the village. Although, new governing systems have been established in the village, they have not been able to fulfill the needs and aspirations of rural people living in the village. The formal governing systems have contributed to distant villagers form informal leaderships and systems that were existed in the village, but in return, the formal institutions were not close to the lives of people. The laws and procedures that have been introduced as part of governing rules have not served the people in the village adequately, but helped to alienate villagers on those laws and rules.

Ranaweera Banda (2013:175-176) explained that "in the past, there were three important social institutions in the traditional Sinhalese village, which were instrumental in preserving and continuing the local culture. Among them, the Buddhist temple of the village was the place of moral education and learning. The Kattadiya (ritual specialist) was the mediator between the man and nature. The Vedamahaththaya (native medical practitioner) was the person who attended to villagers' illness both physical and psychological. None of these institutions demand any payments for their services. These three institutions are represented today by school and hospital/ medical centre and they are profit-oriented. Mutual help was a norm that bounded villagers in maintaining a unity among them. It has not disappeared altogether but has become more formalized"

In Kudagama, all these three types of local leaderships were there in the past. The Buddhist priest of the temple has provided leadership in advising people not only for the religious activities, but also for many other activities including involvements in the agriculture sector, collectiveness and live in peace and harmony. There were many Kattadiyas in Kudagama as people believe rituals for many of the illnesses that they had to face. Kattadiya and Vedamahaththaya were able to treat all most all the illnesses that people suffered in the past.

Sri Lanka is regarded as one of the countries where the Traditional Buddhist Theravāda or Hinayāna system remains very strong. The Theravāda Tradition of Sri Lanka evolved in a specific way where Buddhist Monks occupied centre stage in private and public affairs of it followers (Gombrich 2006: 30-31). The Mahâvamsa has recorded the nature and content of the relation that the state had maintained with Buddhist Clergy and their involvement in governing the affairs of the country. It had charted out the conflict and cordial relationship the Sangha has had with individual kings and dynasties (Seneviratne 2001: 33-44). Similarly, in Kudagama as well, almost all the residents of the village have had high regards for the Buddhist monk. People have obtained various services from him not only on the religious lesions but also on various other 
advices when they wanted such. Although, traditionally, the Buddhist monk has provided moral education, later on he has converted to a person that provides various other services to the villagers including helping to sort out land disputes, family conflicts etc.

Meantime, the change processes that have been taken place towards capitalist socioeconomic system could have been other reasons for such responses. The same argument supported by anthropological studies in Sri Lanka. For example, Obeysekera (1972), Gombrich \& Obeysekere (1988) has mentioned that "As results of modernisation of the village as its social institutions, livelihood systems and cultural norms have considerably changed the role of Buddhist monk in the village has also modernised.

The Vedamahaththaya in Kudagama has used both local medicines that are freely available in and around the village and some kinds of rituals which contributes to the mine which is also important in the traditional rural society in order to treat various kinds of illnesses that the villagers suffer. Treatments have been done on free of charge and people in the village have got together and helped in the treatment process many ways. This process highlights the collective nature of the culture that has practiced by the village people in Kudagama around 20-25 years back. However, at present, this situation has considerably changed and villagers are more encouraged to get treatments from western medicine which is promoted by the capitalist economic system in the era of globalization.

The changed situation towards Vedamahaththaya has brought two types of results in the village. On one hand, the people in Kudagama village now taking treatments from western medicine which has been accepted as a most developed treatment method for almost all the illnesses that people suffer in the present society. Therefore, it can be assumed that people in this village also get considerably better treatments for the illnesses that they suffer. However, in the meantime, negative aspects of this system in the village are that, people moving away from the nature, local treatment methods, local leaderships and collectiveness. The earlier systems of treatments were included use of local medicines easily found from the natural forest of the village and its vicinity. The treatments were done by the local medicinal practitioner available in the village and the villagers' get-together and helped the patient collectively. There were no involvements of money in this system as the treatments were done on free of charge. All these collective values have been abandoned due to the changed situation in the village at present.

In this paper, the term alienation has been used to explain the situation that the laws and systems have been designed by the ordinary people based on their cultural norms and values and specifically as kinds of prevention measures, however, the same is decide by the power groups or formal governing mechanisms which contributes to the marginalization of ordinary people.

Significant contribution towards global governing mechanisms in the Kudagama was revealed as results of interventions by the forest department in the village. The forest department was started as the Office of the Conservator of Forests in 1887 denoting the commencement of forest conservation and scientific forestry in Sri 
Lanka $^{1}$. The main aim of the forest department is conservation of forest in the country. Since Sinharaja was the largest forest in Sri Lanka, the forest department has responsibilities to conserve the Sinharaja forest in and around Kudagama village as well. Since the year 1977, the forest department has given high priority for protecting the reserve and in 1978 began planting Pinus caribaea along the periphery to establish a live boundary (de Zoysa \& Raheem, 1993).

When applying the world polity theory (Meyer, 1997) to explain the interventions of the forest department in the Kudagama village, it is evidenced that the forest department has intervened as a rationalised actor that systematically organised and operate according to the formal rules of nation state. Those rules that implemented by the forest department in Kudagama primarily not comes from the national government but also they have roots in transnational institutions like United Nations (UN) who are advocating environment sustainability or conservation of environment like the Sinharaja forest.

Both the leaderships and governance are more related to the power in the society. Taking macro analysis one of the pioneer functionalists $^{2}$, Max Weber (1864-1920) has theorized the power and authority in the society. As per this perspective, the

1 The Forest Department Sri Lanka, Government of Sri Lanka. Retrieved from http://www.forestdept.gov.lk/web/ Accessed on $12^{\text {th }}$ August 2016

2 Prominent functionalist of the sociology include Herbert Spencer (1820 -1903), Emile Durkheim (1858-1917), Talcott Parsons (1902-1979), Max Weber and Robert Merton (1910-2003). inequalities are arranged in the society by the three dimensions of power namely (1) economic, (2) prestige and (3) pure power. These three type of power is contributes to form three groups as the class, the status group and the party. Accordingly, the power is the capacity to get done what you want. As per this perspective, the leaderships of both informal and formal and also governance systems in Kudagama also maintain certain power. These institutes operate towards accumulation of power. It was revealed that in the past, the power in the village has been with the traditional leaderships of village temple, native doctor or headman. In Kudagama they have been regarded with prestige stage by the villagers. However, at present, these leaderships and governance systems have been taken over by the formal and professional leaderships and institutions. As per the functionalist perspectives, these leaders and as well as governance systems contributes to maintain the social order and its functions in the society. Weber in his most popular publication on Protestant Ethic and the Spirit of Capitalism (1985) accepted that the modern western societies are capitalist in nature and argued that the Protestant ethics and the spirit of capitalism is very much alike. In the process of acting the village leaders and governance mechanism of getting done what they want restrictions from others are not considered. Therefore, the functionalist view is that the whole governing institutes and leaderships irrespective of formal or informal contributes to maintain the social order and its functions. Accordingly, the traditional leaders in the Kudagama which include the native doctor, village headman and Buddhist monk of the village temple helped to maintain society's functions positively. However, the Marxist or conflict analysis argued that the traditional leaders and the 
governing mechanisms contribute to the exploitation and they did not allow general people in the village to come up and develop their own ways. The powers vested with the governance systems and leaderships have been used to marginalise and exploit the ordinary villagers.

\section{IMPACTS OF GLOBAL TRADING AND MARKETING}

Under the social impact of global trading and marketing, the study concentrated on three interrelated variables namely adaptations to the capitalist economic system, economic dependency and livelihood insecurity.

In the theory of "Risk Society", Ulrik Beck( 1992) explained that the social order in the early days of modernization was centered on economics, especially the distribution of economic output, the risk are primarily associated with income and wealth. Accordingly, everyone in the society without any boundaries of class, although in higher class or lower class have to face risks due to the centrally focused economic systems. The earlier system of selfsufficiency agriculture based livelihood provided the basic needs of the people. There were no such risks involved in that system as the cultivation provided them enough harvest for consumption. Since the system was based on collective and sharing basis and also use of tools and other raw materials were primitive nature without high cost, whatever produced were simply used for consumption as there were no need of marketing their products. Although at the initial stages of transforming to cash crop economy, the villagers have enjoyed some kinds of economic gain, it has now reduced due to various reasons including increased cost of production and decreased of harvest.

In early days, villagers have been engaged in subsistence agricultural work and those cultivation have produced enough for their consumption. The people had no issue as they didn't want to bring anything out side as what they produced was enough for their consumption. Due to this system, there was no any dependency with outside. However, later on, they have transformed from this sustainable system to a dependency system. Even the paddy field that provided them enough rice to consume has been converted in to cash crop lands and planted tea. Although, tea cultivation is still providing basic needs for survival of the people, it is not enough for people to satisfy with their needs.

The people have to depend on private entrepreneurs to buy their products on daily basis. If the Lorries don't come to buy tea leaves in the afternoon of each day, they lose their livelihood. The private entrepreneurs come to the village on daily basis and buy the products from the villagers, but they made payments later on through bank accounts. This system seems like a chain of dependency that has been created by the cash crop economy promoted by the multinational and transnational actors in the age of globalization.

Ritzer (1996, 2011) described the idea of glocalization which means that "global institutions are brought into the local community. For example McDonald's has a policy of providing a standardized service wherever they have franchises; as such it is a globalizing force". The concept of McDonalisation is one of the key impacts of 
globalization. Although, large scale multinational companies or transnational companies are not visible in the Kudagama village yet, it was found that their products and other interventions have reached the Kudagama invisibly. The tea cultivation has created economic dependency of people with outside. They can't further rely on their own subsistence agriculture systems, they have transformed to new consumption patterns, and also they don't have leisure time to engage in social and other cultural activities as they are bounded in the capitalist economic system.

The discussion and analysis based on both qualitative and quantitative data comparing with theories revealed the level of transformation that has been taken place in Kudagama village towards the capitalist economic system. Accordingly, there was no any system of marketing or producing for markets in the past. People had idea of what they need for their consumptions as well as the quantity that they required from each items. Therefore, they cultivated those items in sufficient quantity. Whenever there are some excess, they had a system of sharing with their neighbors and relatives. This nature of livelihood system has been existed with collective cultivation and consumption. The engagement in the agricultural work has been done collectively and it has promoted the togetherness of the people in the village. Both men and women in the families have shared the responsibilities in this livelihood system. The engagement of women in preparing and taking foods to the agriculture field provides evidence of their engagement in the productive role ${ }^{3}$ as well. Villagers'

\footnotetext{
${ }^{3}$ Studies in Gender highlights that there are three gender roles( Triple role) as production role, reproduction role and management role ( See Moser, 1993, Pannilage 2013:42)
}

participation in collective events of the agriculture activities such as forest cleaning, land preparation and harvesting as a group through traditional systems of Aththam or Kaiya provide good examples of shared culture of the villagers during those days.

While the main livelihoods have been transferred to tea cultivation, the villagers in Kudagama also engaged in cultivation of some of other marketable products such as spices that have high market value. In the capitalist economic system, people have to compete with each other for their survival. This nature of livelihood system then leads to many other social impacts including less significant of social values, collectiveness and togetherness etc as the main trust area is to promote individualism oppose to the earlier system of promoting collectiveness. In such a system, the people who engaged in their own production system transform to a system that they produce for others. When they have to transform to a system of producing for others, automatically, people have to depend on the outside to fulfil their own needs. Ritzer (2011:26) wrote that "alienation occurs because capitalism has evolved into a two-class system in which a few capitalists own the production process, the products, and the labor time of those who work for them. Instead of naturally producing for themselves, people produce unnaturally in capitalist society for a small group of capitalists"

When analyse from the functionalist perspectives, it can be understood that these factors such as transformation of villagers from traditional systems to the modern or capitalist system is taken place in consensus and order that exist in the society, it helped to maintain the social stability as well. The 
symbolic interaction theory is analysing society by addressing the subjective meanings that people impose on objects, events and behaviors. So, the changes taken place in Kudagama in terms of moving away from the nature and indigenous cultural values could understand as part of interactions that based on the meanings that people have given to those events or in other words symbols as explained by symbolic interactionalists. However, according to the conflict theory, social order maintained by domination and not on consensus basis. Those who have power in hands with the greatest political, economic and social resources, dominate the society which leads to the marginalization of others. The modern capitalist system, which imposed by the dominant groups which means the owners of the means of production, considerably contributes to the exploitation as well. Giddens (2013: 125) wrote that "Capitalism differs in a fundamental way from preexisting production systems, because it involves the constant expansion of production and the ever-increasing accumulation of wealth. In traditional production systems, levels of production were fairly static, as they were geared to habitual, customary needs"

\section{CONCLUSION}

The analysis in the paper revealed that there was a considerable level of social change process in the study location as results of outside interventions to the village. Some of the changes that have been taken place in the village could be concluded as a gradual process due to the evolution nature of the society while some of changes could identify as results of the reforms taken place in the western world and imposement to the countries like Sri Lanka mainly through the process of globalization. The globalization process has contributed for the changes in the family and marriage systems of the rural people in Sri Lanka. The traditional family and marriage system which are basic social institutions with direct links to the cultural practices of a village have modernized as results of change process that has been taken place as results of the globalization process. Meantime, the changes taken place in Kudagama village in terms of building market linkages has created long term dependency on transnational institutions, government and private sector. The analysis and findings of the study contributes to conclude that global trading and marketing systems results in transforming subsistence agriculture based livelihoods in to a cash economy where production is leads to the market in oppose to the production for consumption which was the prime objective of cultivation in traditional agricultural societies like Sri Lanka. This process leads to a consumer culture through the interdependency for production and as well as for consumption. The global governing systems that have been established in the village have not been able to fulfill the needs and aspirations of rural people living in the study location. The formal governing systems have contributed to distanced villagers form informal leaderships and systems that were existed in the village, but in return the formal institutions were not close to the lives of people. The laws and procedures that have been introduced as part of governing rules have not served the people in the village adequately but helped to alienate villagers on those laws and rules.

\section{REFERENCE}

Antonio, R.L., (2004) Globalisation: An Asian Perspective on Modernity and Politics in America, Marshall Cavendish, Singapoor 
Beck, U., (1992) The risk society. Toward a new modernity. London, sage

Bryman, A., (2012). Social Research Methods (4 ed.). Oxford, UK : Oxford University Press.

De Zoysa, N., \&. Raheem, R., (1993). Sinharaja: A rain forest in Sri Lanka. Colombo, Sri Lanka:March for Conservation.

Giddens, A., (2009) Sociology (sixth edition), Polity Press, UK and USA

Gombrich, R., (2006). Is the Sri Lankan war a Buddhist fundamentalism?. In Mahinda Deegalle (Ed). Buddhism, Conflict and Violence in Modern Sri Lanka (pp.22-37). London: Routledge. .

Gombrich, R., \& Obeysekere, G. (1988). Buddhism transformed: Religious Changes in Sri Lanka. New Delhi : Motilal Banarsidass Publishers Pvt Ltd.

Held, D. M., (1999). Global Transformations: politics, economics and culture. Cambridge: Polity Press.

Khor, M., (2002), Globalisation and the South: Some Critical Issues, Third World Network, Malaysia.

McCorriston, S., Hemming, D. J., Lamontagne-Godwin, J. D., Osborn, J., Parr, M. J.,

\& Roberts, P. D. (2013). What is the evidence of the impact of agricultural trade liberalisation on food security in developing countries? A systematic review. London: EPPI-Centre, Social
Science Research Unit, Institute of Education, University of London.

Meyer, J. W. (1997). World Society and the Nation-State. American Journal of Sociology. 103(1), 144-181.

Moser, C.O. N. (1993). Gender Planning and Development: Theory Practice and Training. London: Routledge

Obeysekere, G. (1972). Religious Symbolism and Political Change in Ceylon. Modern Ceylon Studies, 1(1), 43-63.

Olsen, W. (2004). Triangulation in social research: Qualitative and quantitative methods can really be mixed, . Developments in Sociology, 20(1), 103-118.

Pannilage, U. (2013). Role of Women in Rural Development. Colombo : Gamana ( Gted), Ltd.

Ranaweera Banda R.M. (2013)

Transnational Culture and Expert Knowledge: Responses from a Rural Community in Sri Lanka Author Publication.

Ritzer, G., (2011). Globalization: the Essentials. Wiley Blackwell .

Ritzer, G., (1996). The McDonaldization of Society: An Investigation into the Changing Character of Contemporary Society. Thousand Oaks, Calif: Pine Forge Press.

Robertson, R. (1992). Globalisation: Social Theory and Global Culture. London: Sage.

Rosenau, J., (2003). Distant proximities: Dynamics beyond globalization. Princeton, NJ: Princeton University Press. 
Seneviratne, H. (2001). Buddhist Monks and Ethnic Politics: A War Zone in an Island Paradise. Anthropology Today, 17(2), 33-44.

Turner, B. S., (2011) Religion and Modern Society: Citizenship, Secularisation and the state, Cambridge, Cambridge University Press, UK

Wallerstein, I., ( 1974)The Modern World System: Capitalist Agriculture and the Origins of the European World Economy in the Sixteenth Century, New York: Academic Press.

Youngs, G., ( 2007) International Relations as we Enter the Twenty- first Century. In Kofman Eleonore and Youngs Gillian ( Ed) Globalisation: Theory and Practice ( second edition), Continuum, New York, USA 